\title{
Effect of modified early warning system on rapid response team call outcome
}

\author{
Shahriar Dadkhah ${ }^{*}$, Ekta Shrestha ${ }^{2}$, Aswin Ratna Kansakar ${ }^{2}$, Negar Faramarzi², Amishi Parekh ${ }^{3}$, Lydia Dacenko-Grawe ${ }^{3}$, Sumit Sohal ${ }^{2}$, \\ Mohammed Omer Ahmed Abdalla ${ }^{2}$, Hugo Jose Macchi Cattoni ${ }^{2}$, Bahaa Al- azzam ${ }^{2}$ and Philippos Tsourkas ${ }^{4}$ \\ ${ }^{1}$ Department of Cardiology, Presence Saint Francis Hospital, Wilmette, IL, USA \\ ${ }^{2}$ Department of Internal Medicine, Presence Saint Francis Hospital, Evanston, IL, USA \\ ${ }^{3}$ Presence Saint Francis Hospital, Evanston, IL, USA \\ ${ }^{4}$ Department of Life Sciences, University of Nevada, Las Vegas
}

\begin{abstract}
Background: In-hospital cardiac arrest and death are often heralded by abnormal vital signs hours before the event. The Modified Early Warning Score (MEWS) is a physiological scoring system that assigns risk for clinical deterioration based on vital signs and clinical observation. Here we discuss our experience and effectiveness of implementation of MEWS as an important tool for triggering Rapid Response (RRT) and impact of it on patient outcome.

Methods: We did a retrospective chart review of patients who had RRT called since implementation of our electronic medical record from November 2011 through June 2017 in community-based teaching hospital. The MEWS system at the time of RRT call was implemented in our hospital in 2015 and we compared the outcomes of RRT in Pre-and Post-MEWS era.

Results: A total of 56,532 patients were admitted to the hospital between November 2011 and June 2017, out which 898 patients had RRTs called. There was a significant increase in RRT called from the Pre- to the Post MEWS Era (1.31\% vs $1.97 \%, p=0.03)$. The MEWS score in the Pre-MEWS era was significantly higher than in the Post-MEWS Era (4.39 vs $3.95 p=0.0004)$. After the implementation of MEWS, the percentage of code blue was also decreasing.
\end{abstract}

Conclusion: Implementation of MEWS in our institute has led to an increased number of RRT called and MEWS number at the time of RRT itself has decreased. Hence the utilization of MEWS has proven to be a useful tool in early recognition of deteriorating patients in our institution.

\section{Introduction}

In-hospital cardiac arrest is a major public health concern with an annual incidence of 209,000 in the United States [1]. In-hospital cardiac arrest is preceded by the deterioration of a patient's physiological parameters and vital signs [2]. Identifying and appropriately managing these vital parameters accurately and timely can be helpful in reducing inhospital cardiac events and death [3]. Therefore, the deployment of rapid response (RRT) teams at the first sign of clinical deterioration has been recommended by the Institute for Healthcare Improvement (IHI) when it launched its 100,000 Lives Campaign in 2004 [3]. Various systems for risk assessment in hospitalized patient have been developed [4].

Traditionally, an RRT is activated when a patient meets predefined clinical criteria such as an extreme change in a vital sign or a change in the level of consciousness. However, aggregate weighted systems such as Modified Early Warning Score (MEWS), Shared Early warning System (SEWS), Vitals Early Warning System (ViEWS) etc., have been found to be more accurate for detecting early cardiac arrest and need for ICU transfer [5]. An early warning system, introduced by Morgan, Williams, and Wright in 1997 as the Early Warning System (EWS) [6], and modified to a Modified EWS (MEWS) subsequently in the United Kingdom [7], is a simple systematic scoring system which uses five physiological parameters of patient's vital signs including heart rate, respiratory rate, systolic blood pressure, temperature and consciousness level. The MEWS systems have been implemented to identify those at risk of clinical deterioration in non-ICU wards $[3,8]$ and can predict those at risk of cardiac arrest and death within 48 hours [9-11]. MEWS systems have not only been used for recognition of early signs of clinical deterioration but also for triggering the need for more intensive care such as increased nursing attention, informing the care provider, or activating an RRT team [12].

In 2015, our community-based teaching hospital with an average of 1,0000 inpatient admissions per year, implemented a MEWS system at the time of RRT. The objective of our study was to determine the effectiveness of MEWS implementation on RRT calls and patient outcomes.

\section{Methods and materials}

This study is based on a retrospective chart review of all in-patients who had an RRT called since implementation of our electronic medical record from November 2011 to June 2017. The institutional review board of our institution approved this study.

Inclusion criteria consisted of any adult patient admitted to the medical or surgical floor during the study period. Exclusion criteria were patients admitted directly to the intensive care unit (ICU) from

${ }^{\star}$ Correspondence to: Shahriar Dadkhah, Department of Cardiology, Presence Saint Francis Hospital, 1500 Sheridan, Unit 2J, Wilmette, IL, USA, 6009, Tel: 847-3636052; Fax: 847-864-0088; E-mail: dadkhahsc@aol.com

Received: December 04, 2018; Accepted: December 12, 2018; Published: December 17, 2018 
the emergency department (ED) or operating room and patients younger than 18 years. All demographic data were collected from the electronic health records. The data was then divided into two periods; November 2011-January 2015 before MEWS was used (PreMEWS Era) and January 2015- June 2017 after MEWS was used for RRT activation (Post-MEWS Era). For the Pre-MEWS Era, MEWS was calculated retrospectively post-hoc at the time of this study. The primary outcomes of our study were mortality and post-hospitalization disposition. Mortality data was obtained via chart review.

For continuous data T-test was performed and for categorical data Binomial test was used for data analysis. $P$-value less than 0.05 is defined as statistically significant.

\section{Results}

The total number of patients admitted from November 2011 through June 2017 was 56,532 with 898 RRT's called during this time frame. Demographic data is presented in the Table 1.

In 2015, MEWS measurement was started in a protocolled manner. Table 2 summarized the primary and secondary outcomes in our study in the Pre- and Post-MEWS Eras. There was a statistically significant increase in the percentage of RRT's per patient admission demonstrated after MEWS implementation $(p=0.03)$.

Additionally, there was a statistically significant difference in the actual MEWS in the pre-MEWS Era compared to post-MEWS Era ( 4.39 versus $3.95, p=0.0004$ ). The time from admission to activation of RRT in the Pre-MEWS Era compared to Post-MEWS Era also showed a decreasing trend (114.87 minutes to 95.7 minutes $p=0.1$ ).

We also identified a reduction in the percentage of RRT patients who ended up being transferred to a higher level of care since implementation of the MEW Pre-MEWS compared to post-MEWS Era ( $60 \%$ versus $43 \%$ respectively, $p=0.03$ ) but overall there seemed to be no change in the outcome of the patients who had an RRT activated. A subgroup analysis was done in only patients who were not transferred to higher care, which did show an uptrend in patients discharged home in the Post-MEWS Era, but it was statistically insignificant (Table 3).

Table 1. Demographic data in Pre- and Post-MEWS Era patient population

\begin{tabular}{|c|c|c|c|}
\hline & Pre-MEWS Era & Post-MEWS Era & p-value \\
\hline Mean Age (in years) & 70 & 67 & $<0.05$ \\
\hline Male & $217(53.8 \%)$ & $243(49.1 \%)$ & 0.15 \\
\hline Co-morbidities & \multicolumn{3}{|l|}{} \\
\hline Cancer & 98 & 119 & 0.41 \\
\hline Hypertension & 298 & 352 & $<0.05$ \\
\hline Diabetes Mellitus & 157 & 204 & 0.49 \\
\hline
\end{tabular}

Table 2. Results

\begin{tabular}{|l|c|c|c|}
\hline \multicolumn{1}{|c|}{} & $\begin{array}{c}\text { Pre-MEWS } \\
\text { Era }\end{array}$ & $\begin{array}{c}\text { Post-MEWS } \\
\text { Era }\end{array}$ & p-value \\
\hline Total Admissions & 30713 & 25819 & \\
\hline Number of RRT calls & $403(1.31 \%)$ & $495(1.97 \%)$ & 0.03 \\
\hline Average MEWS score at time of RRT & 4.39 & 3.95 & 0.0004 \\
\hline Time to RRT call from admission (in min) & 114.87 & 94.7 & 0.1 \\
\hline RRT transferred to higher care & $245(60.04 \%)$ & $213(43.04 \%)$ & 0.003 \\
\hline Mean outcome (per 100 RRT) & \multicolumn{3}{|c|}{} \\
\hline Mortality & 19.95 & 16.4 & 0.2 \\
\hline Home & 39.83 & 45 & 0.2 \\
\hline Hospice & 40.2 & 38.4 & 0.4 \\
\hline Total Code Blue (per 100 admissions) & 1.4 & 1.2 & 0.015 \\
\hline
\end{tabular}

RRT: Rapid Response
Table 3. Outcomes in patients who did not transfer to higher care unit

\begin{tabular}{|c|c|c|c|}
\hline & Pre-MEWS Era & Post-MEWS Era & p-value \\
\hline Mortality & 17.9 & 9.4 & 0.12 \\
\hline Home & 39.6 & 51.9 & 0.05 \\
\hline Hospice & 42.4 & 38.5 & 0.3 \\
\hline
\end{tabular}

Additionally, with the implementation of MEWS, the number of inhospital cardiac arrests decreased from $1.4 \%$ in the Pre-MEWS group to $1.2 \%$ Post-MEWS group $(p=0.015)$ per 100 Code blues identified after RRT. Also, there was a reduction in the percentage of code blue calls after an RRT activation ( $4.2 \%$ vs. $3.8 \%, p=0.2)$.

\section{Discussion}

It is now well known that in-hospital cardiac arrests are frequently heralded by changes in physiological parameters. In 2005 the IHI recommended implementing rapid response teams as its top recommendation to decrease in-hospital mortality and morbidity [4]. Since then, multiple hospitals including ours, initiated rapid response teams. However, various methods to assess the decline in physiological parameters have been used in multiple institutions [13]. MEWS is one of the most studied scoring systems used and has been shown to be a useful tool to predict in hospital mortality $[14,15]$. Also, instead of using single trigger criteria or clinical assumption made by nurses, clinicians and family members, MEWS system seems to be more objective and systematic way to recognize patient's deterioration. We started using MEWS as our criteria to call a rapid response since 2015.

This study demonstrates that MEWS implementation increases the total number of RRT calls. This is consistent with other studies done in the past $[14,16]$. This is potentially because of the ease of using an objective scoring system, which may give more confidence to providers to call an RRT. With a decrease in average MEWS on admission and shorter duration from admission to rapid response call shown, it would suggest that the providers are identifying deterioration of patient's clinical status as early as possible. Hence it would seem that MEWS is an effective tool for stratification of the clinical changes in a patient's condition. The decrease in transfer to a higher-level care unit that was seen would also support this implication.

Although RRT patients in the Post-MEWS era didn't show any statistically significant changes in mortality or discharge home/selfcare and hospice care, those who had an RRT activated but who did not transfer to a higher level of care seemed to have more favourable outcomes. This is potentially because of heightened care post-RRT on the general ward. All these results represent an earlier detection of clinical deterioration and improvement of outcomes.

Additionally, there was a drop in the total number of code blues called in the hospital after implementation of MEWS. This further confirms the thought that was stated in the Journal on Quality and Patients Safety [17], that code blue events could be prevented using MEWS. However, there was no significant changes seen in the number of code blues called in the patients in whom an RRT was called suggesting that although RRT could prevent code blues from happening, they can still precede a cardiopulmonary arrest.

Our study has several limitations. First, this was done in a single institution with 24-hr internal medicine resident coverage, which would not be applicable in a general hospital. Also, being a retrospective study, our findings could be confounded by other unknown variables that could affect in-hospital mortality. There is also the fact that although the authors made all attempts to verify all data corrected, especially in 
the Pre-MEWS group, some data were incomplete and respiratory rate is poorly assessed and might not be accurate.

\section{Conclusion}

Implementation of MEWS has provided a systematic way to identify at-risk patients and assist with RRT calls. Compared to a Pre-MEWS Era, MEWS implementation causes an increase in the percentage of admission for which an RRT is called and those for whom an RRT is called have a lower MEWS suggesting earlier identification of atrisk patients. MEWS systems affect mortality and discharge to home/ self-care and hospice but there is no statistically significant difference compared to a pre-MEWS period. Finally, total-in hospital cardiac arrests reduced although there was no statically significant difference in code blue calls after an RRT.

\section{References}

1. Kronick SL, Kurz MC, Lin S, Edelson DP, Berg RA, et al. (2015) Part 4: Systems of Care and Continuous Quality Improvement: 2015 American Heart Association Guidelines Update for Cardiopulmonary Resuscitation and Emergency Cardiovascular Care. Circulation 132: S397-413. [Crossref]

2. Schein RM, Hazday N, Pena M, Ruben BH, Sprung CL (1990) Clinical Antecedents to In-Hospital Cardiopulmonary Arrest. Chest 98: 1388-1392. [Crossref]

3. Smith ME, Chiovaro JC, O’Neil M, Kansagara D, Quiñones AR, et al. (2014) Early Warning System Scores for Clinical Deterioration in Hospitalized Patients: A Systematic Review. Ann Am Thorac Soc 11: 1454-1465. [Crossref]

4. Jansen JO, Cuthbertson BH (2010) Detecting critical illness outside the ICU: the role of track and trigger systems. Curr Opin Crit Care 16: 184-190. [Crossref]

5. Churpek MM, Yuen TC, Edelson DP (2013) Risk Stratification of Hospitalized Patients on the Wards. Current neurology and neuroscience reports. Chest 143: 1758-1765. [Crossref]

6. Morgan R, Williams F, Wright MM (1997) An early warning scoring system for detecting developing critical illness.
7. Stenhouse C, Coates S, Tivey M, Allison P, Parker T (2000) Prospective evaluation of a modified Early Warning Score to aid earlier detection of patients developing critical illness on a general surgical ward. Br J Anaesth 84: 663.

8. Kim WY, Shin YJ, Lee JM, Jin WH, Koh Y, et al. (2015) Modified Early Warning Score Changes Prior to Cardiac Arrest in General Wards. PLoS One 10: e0130523. [Crossref]

9. Wang AY, Fang CC, Chen SC, Tsai SH, Kao WF (2015) Periarrest Modified Early Warning Score (MEWS) predicts the outcome of in-hospital cardiac arrest. $J$ Formos Med Assoc 115 :76-82. [Crossref]

10. Fullerton JN, Price CL, Silvey NE, Brace SJ, Perkins GD (2012) Is the Modified Early Warning Score (MEWS) superior to clinician judgement in detecting critical illness in the pre-hospital environment? Resuscitation 83: 557-62. [Crossref]

11. Johnson S, Nileswar A (2015) Effectiveness of Modified Early Warning Score (MEWS) in the Outcome of In-Hospital Adult Cardiac Arrests in a Tertiary Hospital. J Pulm Respir Med 05: 1000285

12. Whittington J, White R, Haig KM, Slock M (2007) Using an automated risk assessment report to identify patients at risk for clinical deterioration. Jt Comm J Qual Patient Saf 33: 569-574. [Crossref]

13. 5 Million Lives Campaign. Getting Started Kit: Rapid Response Teams. Cambridge, MA: Institute for Healthcare Improvement. Available at: www.ihi.org.

14. Cei M, Bartolomei C, Mumoli N (2009) In-hospital mortality and morbidity of elderly medical patients can be predicted at admission by the Modified Early Warning Score: a prospective study. Int J Clin Pract 63: 591-595. [Crossref]

15. Ludikhuize J, Borgert M, Binnekade J, Subbe C, Dongelmans D, et al. (2014) Standardized measurement of the Modified Early Warning Score results in enhanced implementation of a Rapid Response System: A quasi-experimental study. Resuscitation 85: 676-682. [Crossref].

16. Mathukia C, Fan W, Vadyak K, Biege C, Krishnamurthy M (2015) Modified Early Warning System improves patient safety and clinical outcomes in an academic community hospital. J Community Hosp Intern Med Perspect 5: 26716. [Crossref]

17. Maupin JM, Roth DJ, Krapes JM (2009) Use of the Modified Early Warning Score Decreases Code Blue Events. Jt Comm J Qual Patient Saf 35: 598-603. [Crossref]

Copyright: $(2018$ Shrestha E. This is an open-access article distributed under the terms of the Creative Commons Attribution License, which permits unrestricted use, distribution, and reproduction in any medium, provided the original author and source are credited. 